\title{
Real Time Breath Processing Based Embedded Vehicle Control Using WSN
}

\author{
Umeshkumar Jaiswar'1, Sanjna S. Repal² \\ ${ }^{1}$ P.G. student, Department of Electronics and Telecommunication Engineering, MCT's RGIT College, Andheri (W), Mumbai, Maharashtra, \\ India
}

${ }^{2}$ Assistant Professor, Department of Electronics and Telecommunication Engineering, MCT's RGIT College, Andheri (W), Mumbai, Maharashtra, India

\begin{abstract}
Now a day, Quadriplegic people depend on powered wheelchairs for mobility which are rare, complicated and expensive. Considering the application of these wheelchairs, the digital type interface is not desirable, because control of wheelchair need preciseness and quickness for safe operation. The purpose of this project is to design a wireless powered wheelchair with novel control system using user's breath pressure and head motion. The two interfacing devices that operate the wheelchair [mounted on cap (head)] are used. Breath pressure (Exhaling and Inhaling) of person and head motions are measured using these devices. Depending upon the breath taken in and out the wheelchair function activates and it moves forward, backward, left and right directions with the help of accelerometer. With this new technique health of the person is monitored with the help of breath pressure without using any kind of sensors like temp sensor, pulse oximetry (SpO2) sensor, heartbeat sensor etc. Motion of wheelchair is controlled wirelessly using Zigbee transceiver. In this paper microcontroller system that enables standard electric wheelchair control by breath and head motion is presented.
\end{abstract}

Keywords: Accelerometer, ARM7 microprocessor, MIC, ZigBee, Proximity sensor, DC motors.

\section{Introduction}

People with physical disabilities (Quadriplegia) and partial paralysis always find difficulty to navigate their normal work in life. After paralysis or physical disability, the wheelchair is the most common means of locomotion for such people. In the field of robotics, embedded system and artificial intelligence a successful designs are been developed, to easily solve this matter at very low cost with more flexibility [1]. In this paper the wheelchair is controlled from several meters wirelessly with the help of human breathe and head motions. Some existing wheelchairs are fitted with PC for their operation. But making use of the PC along with the wheelchair makes it bulkier and increases complexity. This complexity is reduced by making use of the accelerometer (WSN). The size of accelerometer is very compact and placed on the cap. Other existing systems that used similar kind of sensors are wired, which again increases the complexity of the wheelchair system. They also limit the long range communication [2]. This complexity is reduced by using ZigBee technology. Because signals can be transmit through ZigBee over large distances.

In this paper, basically a wheelchair is designed to control with the help of breath pressure (inhalation and exhalation of breath) using MIC and head movements. Accelerometer (which is mounted on cap) is controlled by person's breath pressure and depending upon the breath, the wheelchair moves into desired directions with the help of accelerometer (ADXL335). User just needs to breathe in and out to activate the system and move the wheelchair. The direction of the wheelchair and its speed depend on how the user tilts their head. The user tilts his/her head at an angle, the wheelchair turns in the desired directions. The prototype consists of the control unit (Accelerometer and MIC) and the wheelchair unit. The accelerometer is used to collect head motion data and user breath pressure is measured by MIC. To process these data, a novel algorithm is implemented using a microcontroller (LPC2148). The output of the control unit is given through ZigBee module to the wheelchair unit, which is used to steering the wheelchair with the user's command [1].

Breath samples of individual participants are taken using breath sensing device (MIC). Experiments are done with all collected data (samples) and achieved a range of normal, low and high breath rate. Breath rate is also used to monitor health status of the user. In case of high or low breath rate, the wheelchair will stop and until the breath rate of user does not become normal, it will not move in any direction. Data communication between control unit (Accelerometer and MIC) and wheelchair unit is processed by using ZigBee transceiver (nrf 24L01+) module. This wheelchair is controlled automatically by wireless sensor network (WSN).

\section{System Architecture}

The Architecture of our system is composed of two parts: Control unit (Transmitter part) and Wheelchair unit (Receiver part)

\subsection{Control Unit}

In control unit, an Accelerometer (for controlling the movement), MIC (for detect the breath pressure), LM386 IC (signal conditioning for breath signals), LCD (to display breath rates) and Buzzer (to indicate the hard conditions) are used. Breath input, captured by microphone is given to the microcontroller (LPC2148) which activates the control unit and allows the wheelchair to move in required direction using head motions. Fig.1 shows the block diagram of the control unit. The user breath rates display on LCD. If breath rate 


\section{International Journal of Science and Research (IJSR) \\ ISSN (Online): 2319-7064}

Index Copernicus Value (2013): 6.14 | Impact Factor (2015): 6.391

increases or decreases (High breath rate and Low breath rate), in that situation the buzzer will generate sound. If user does not breathe properly, wheelchair motions will stop automatically. In this way health status of the person is monitored. The head motion information is collected by the accelerometer device, whose output is directly connected to the microcontroller and then the processed data/command is transmitted to the wheelchair unit through wireless transceiver (ZigBee module) [1].



Figure 1: Block Diagram of Control Unit (Transmitter Part)

\subsection{Wheelchair Unit}

The output of the Control system is connected with the wheelchair unit, which is used to position the wheelchair with the user's command. The same data or command, which is transmitted by control unit, is received at wheelchair unit (Receiver part) by the Zigbee module. DC Motors, which are interfaced to the controller through the motor driver IC (L293D), control the wheelchair in given directions. All movement commands are displayed on LCD. Fig. 2 shows the block diagram of the wheelchair unit. A proximity sensor (Front side of wheelchair) and obstacle sensors (Other sides of wheelchair) is used to protect the wheelchair from the wall and any other obstacles [1].

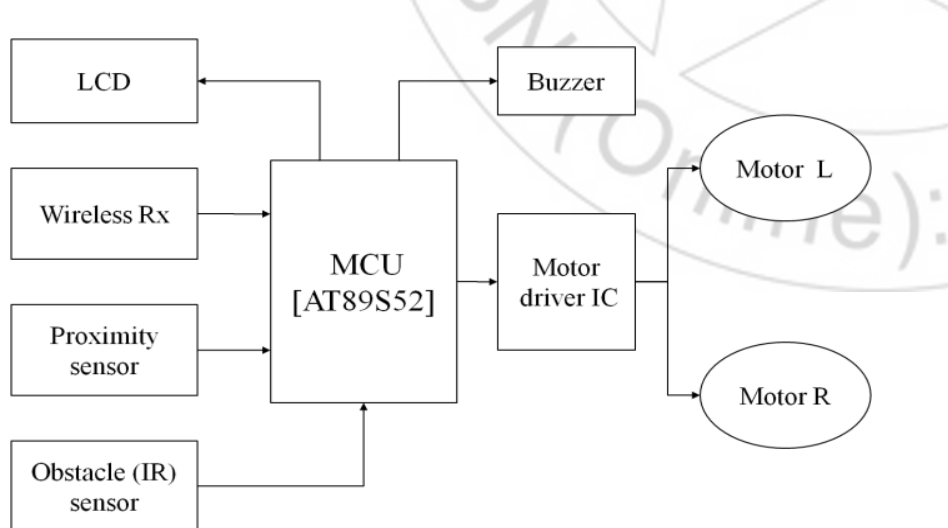

Figure 2: Block Diagram of Wheelchair Unit (Receiver Part)

\section{Schematics}

The Circuit diagrams or Schematics of our wireless embedded system are presented below:

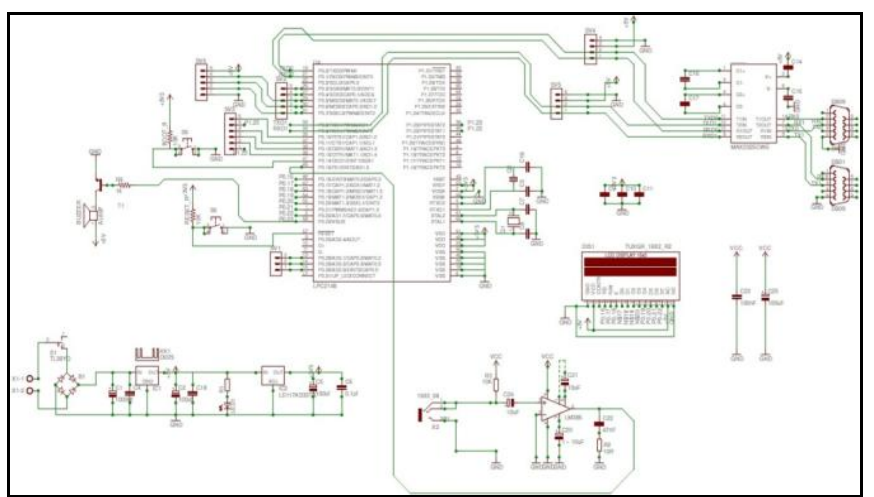

Figure 3: Circuit Diagram of Control Unit

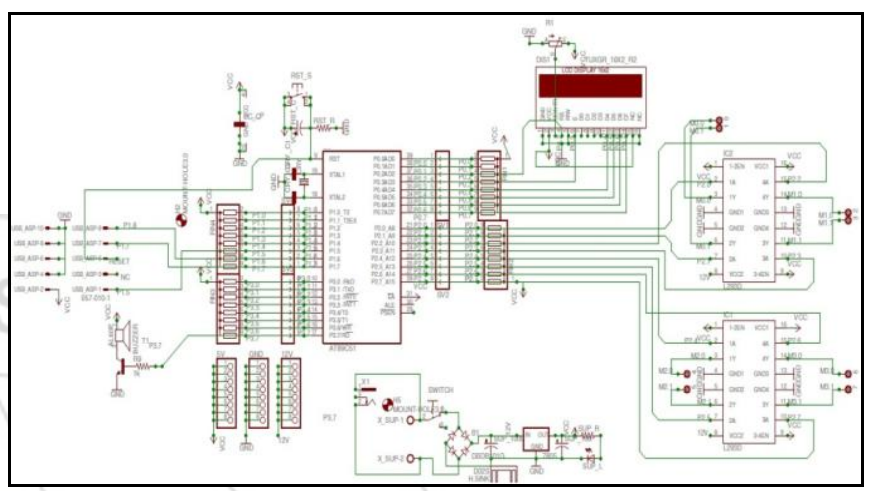

Figure 4: Circuit Diagram of Wheelchair Unit

\section{Real Hardware Implementation of System}

The images of real hardware designs of system are given below:

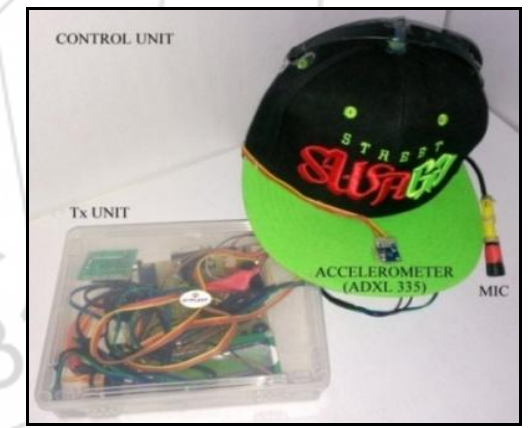

Figure 5: Real Hardware Image of Control Unit

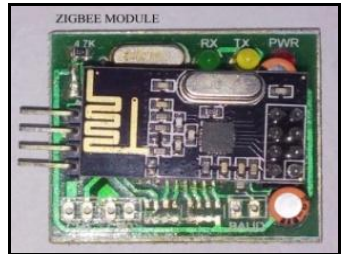

Figure 6: ZigBee Module 


\section{International Journal of Science and Research (IJSR) \\ ISSN (Online): 2319-7064}

Index Copernicus Value (2013): 6.14 | Impact Factor (2015): 6.391

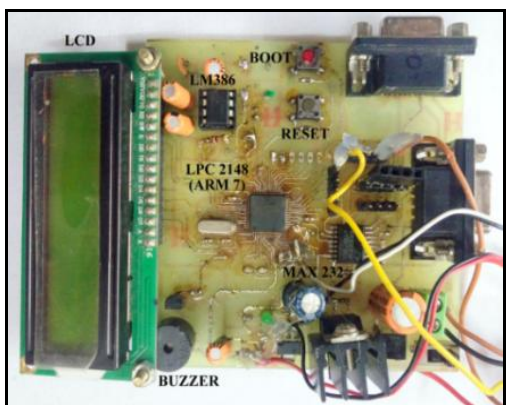

Figure 7: Main Part of Control Unit

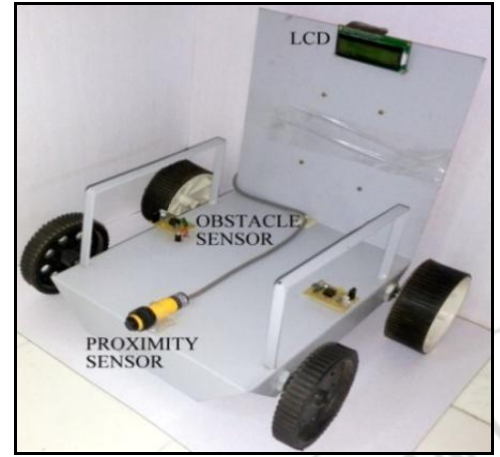

Figure 8: Real Hardware Image of Wheelchair Unit

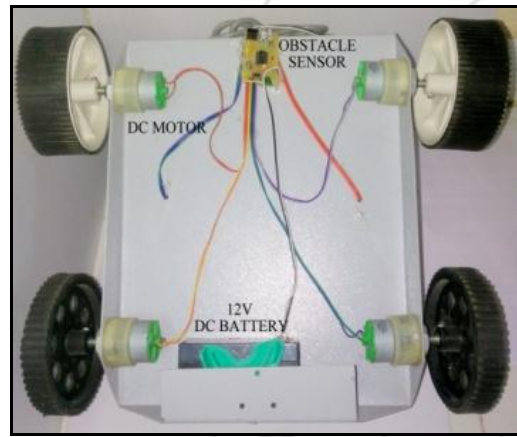

Figure 9: DC Motors, Battery and Obstacle Sensor

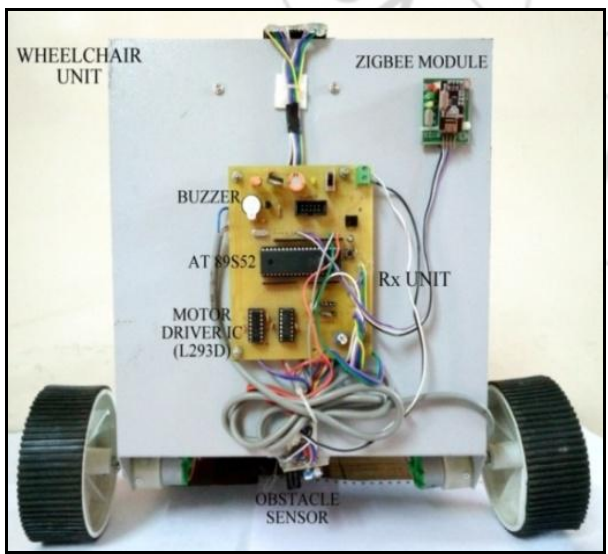

Figure 10: Main Part of Wheelchair Unit

\section{Design Description}

The design description and system modules of our embedded system consist of two main sections:

\subsection{Hardware Description}

In this project, LPC2148 microcontroller based on 32-bit ARM7 TDMI-S is used to access the data from Microphone and accelerometer. ARM7 microprocessor is used to process all data in real time. Accelerometer (3-axis) is used to recognized head motion to control the wheelchair and MIC is used to detect user's breath pressure. To enhance output of air flow sensor, signal conditioning circuit (LM386 IC) is used. Therefore the output of the signal conditioning circuit will directly connected to the microcontroller. As the processing is carried out on digital data, these analog data will be converted into digital data by using ADC which is inbuilt in LPC2148 microcontroller.

\subsubsection{LPC2148 Microcontroller}

The LPC2148 microcontroller is based on a 32/16 bit ARM7TDMI-S CPU with real-time emulation and embedded trace support, that combines the microcontroller with embedded high speed flash memory of $512 \mathrm{kB}$. A 128-bit wide memory interface and unique accelerator architecture enable 32-bit code execution at the maximum clock rate up to $60 \mathrm{MHz}$. For critical code size applications, the alternative 16-bit Thumb mode reduces code by more than $30 \%$ with minimal performance penalty. Due to its tiny size and low power consumption, LPC2148 is ideal for those applications where miniaturization is a key requirement, such as access control and point-of-sale. A blend of serial communications interfaces ranging from a USB 2.0 Full Speed device, multiple UARTs, SPI, SSP to $\mathrm{I}^{2} \mathrm{C}$-Bus, and on-chip SRAM of $40 \mathrm{kB}$, make this device very well suited for communication gateways and protocol converters, soft modems, air vibration recognition and low end imaging, providing both large buffer size and high processing power. Various 32-bit timers, dual 10-bit ADCs, single 10-bit DAC, PWM channels and 45 fast GPIO lines with up to nine edge or level sensitive external interrupt pins make this microcontroller particularly suitable for industrial control and medical systems [1], [12].

The LPC2148 microcontroller has many features, some of which are describe as follows:

\section{(a) ARM7 Microprocessor:}

The LPC2148 is embedded with ARM7TDMI-S microprocessor. The TDMI-S stands for 16-bit Thumb + JTAG Debug + fast Multiplier + enhanced ICE + Synthesizable core. Where T: supports both ARM (32-bit) and Thumb (16-bit) instruction sets, D: Contains Joint Test Action Group (JTAG) Debug extensions, M: Enhanced 32x8 Multiplier block, I: Embedded In-Circuit Emulator (ICE) macro cell, S: Synthesizable (i.e. distributed as Register Transfer Level (RTL) rather than a hardened layout).

The ARM7TDMI-S is a general purpose 32-bit microprocessor, which offers high performance and very low power consumption. The ARM architecture is based on Reduced Instruction Set Computer (RISC) principles, and the instruction set and related decode mechanism are much simpler than those of micro programmed Complex Instruction Set Computers (CISC). This simplicity results in a high instruction throughput and impressive real-time interrupt response from a small and cost-effective processor core. Pipeline techniques are employed so that all parts of the processing and memory systems can operate continuously. 


\section{International Journal of Science and Research (IJSR) \\ ISSN (Online): 2319-7064}

Index Copernicus Value (2013): 6.14 | Impact Factor (2015): 6.391

Typically, while one instruction is being executed, its successor is being decoded, and a third instruction is being fetched from memory.

The ARM7TDMI-S processor also employs a unique architectural strategy known as THUMB, which makes it ideally suited to high-volume applications with memory restrictions, or applications where code density is an issue. The key idea behind THUMB is that of a super-reduced instruction set. Essentially, the ARM7TDMI-S processor has two instruction sets:

- The standard 32-bit ARM instruction set.

- A 16-bit THUMB instruction set.

The THUMB set's 16-bit instruction length allows it to approach twice the density of standard ARM code while retaining most of the ARM's performance advantage over a traditional 16-bit processor using 16-bit registers. This is possible because THUMB code operates on the same 32-bit register set as ARM code. THUMB code is able to provide up to $65 \%$ of the code size of ARM, and $160 \%$ of the performance of an equivalent ARM processor connected to a 16-bit memory system.

\section{(b) 10-Bit ADC:}

The LPC2148 contain two analog to digital converters. These converters are single 10-bit successive approximation analog to digital converters. While ADC0 has six channels, ADC1 has eight channels. Therefore, total number of available ADC inputs for LPC2148 is 14. Basic clocking for the A/D converters is provided by the APB clock. A programmable divider is included in each converter, to scale this clock to the $4.5 \mathrm{MHz}$ (max) clock needed by the successive approximation process. A fully accurate conversion requires 11 of these clocks [1], [12].

Features of ADC:

- 10 bit successive approximation analog to digital converter (i.e. two in LPC2148).

- Input multiplexing among 6 or 8 pins (ADC0 and ADC1).

- Power-down mode.

- Measurement ranges $0 \mathrm{~V}$ to $\mathrm{V}_{\mathrm{REF}}$ (typically $3 \mathrm{~V}$; not to exceed $\mathrm{V}_{\mathrm{DDA}}$ voltage level).

- 10 bit conversion time $\geq 2.44 \mu \mathrm{s}$.

- Burst conversion mode for single or multiple inputs.

- Optional conversion on transition on input pin or Timer Match signal.

- Global Start command for both converters.

\subsubsection{Carbon MIC}

The carbon microphone, also known as carbon button microphone or carbon transmitter, is a type of a transducer that converts sound variation/vibration into an electrical signal. It consists of two metal plates separated by granules of carbon. One plate is very thin and faces outward, acting as a diaphragm. When sound waves strike this plate, the pressure on the granules change and it changes the electrical resistance between the plates. Higher pressure lowers the resistance as the granules are pushed closer together. As a steady direct current $(\approx 10 \mathrm{mV})$ is passes between the plates, the varying resistance results in a modulation of the current at the same frequency of the impinging of sound waves [1].



Figure 11: Carbon MIC

\subsubsection{Accelerometer (ADXL335) Device}

The ADXL335 is a thin, small, low power, complete 3 -axis accelerometer with signal conditioned voltage outputs. It measures acceleration with a minimum full-scale range $3 \mathrm{~g}$. This device measures the static acceleration of gravity in tiltsensing applications and dynamic acceleration resulting from motion, shock, or vibration. The ADXL335 has very low power $(\approx 350 \mu \mathrm{A})$. The user selects the bandwidth of the accelerometer using the $\mathrm{CX}, \mathrm{CY}$, and $\mathrm{CZ}$ capacitors at the $\mathrm{X}$ OUT, Y-OUT, and Z-OUT pins. There are few bandwidths that can be selected to suit the task needed. They range from $0.5 \mathrm{~Hz}$ to $1600 \mathrm{~Hz}$ for the $\mathrm{X}$-axis and $\mathrm{Y}$-axis and from $0.5 \mathrm{~Hz}$ to $550 \mathrm{~Hz}$ for the $\mathrm{Z}$-axis.

The output of the ADXL335 has a typical bandwidth of greater than $500 \mathrm{~Hz}$. The signal is filtered at this point to limit aliasing errors. The analog bandwidth is not more than half the analog-to-digital sampling frequency to minimize aliasing. The analog bandwidth can be further decreased to reduce noise and improve resolution [1], [8], [9]. 


\section{International Journal of Science and Research (IJSR) \\ ISSN (Online): 2319-7064}

Index Copernicus Value (2013): 6.14 | Impact Factor (2015): 6.391

protocol engine (Enhanced ShockBust ${ }^{\mathrm{TM}}$ ), suitable for ultra low power wireless applications. The nRF24L01+ is designed for operation in the world wide ISM frequency band at $2.400-2.4835 \mathrm{GHz}$. To design our system with the nRF24L01+, we simply need an MCU and a few external passive components. We can operate and configure the nRF24L01+ through a Serial Peripheral Interface (SPI).The register map, which is accessible through SPI, contains all configuration registers in the nRF24L01+ and is accessible in all operation modes of the chip.



Figure 13: NORDIC nRF24L01+

The nRF24L01+ supports an air data rate of $250 \mathrm{kbps}, 1$ Mbps and 2 Mbps. The high air data rate combined with two powers saving modes make the nRF24L01+ very suitable for ultra low power designs. The nRF24L01+ is drop in compatible with nRF24L01 and on air compatible with nRF2401A, nRF2402, nRF24E1 and nRF24E2. Intermodulation and wideband blocking values in nRF24L01+ are much improved in comparison to the nRF24L01 and the addition of the internal filtering to nRF24L01+ has improved the margins for meeting RF regulatory standards. Internal voltage regulators ensure a high Power Supply Rejection Ratio (PSRR) and a wide power supply [1], [13].

\subsection{Software Description}

Software is a basic building block for the every system which designs the processing and operations. Following softwares are used in designing of this wireless embedded system.

- It includes PCB layout for our wireless monitoring system.

\section{1) For PCB Layout: CadSoft EAGLE.}

- It also includes the coding for LPC2148 and AT89S52 microcontroller.

1) For $\mu \mathrm{C}$ LPC2148: Embedded $C$ language using Keil $\mu$ Vision 4 .

2) For $\mu \mathrm{C}$ AT89S52: Embedded $\mathrm{C}$ language using Keil $\mu$ Vision 3 .

- For Burning, the written programs into $\mu \mathrm{Cs}$, following softwares are used.

1) For $\mu$ C LPC2148: Flash Magic using PL-2303 Usb-toSerial CH340 Driver.

2) For $\mu \mathrm{C}$ AT89S52: Program ISP using USBasp LibUSB Win 32 Devices Driver.

- To display the data transmitted by control unit to the wheelchair unit on PC, we have used the following software.

1) For ZigBee with USB-to-RS232: AccessPort using PL-
2303 Usb-to-Serial CH340 Driver.

To design the circuit diagram, we used CadSoft EAGLE (Easily Applicable Graphical Layout Editor) software which is less complex, easy to learn, easy to understand and user friendly. It is the advance, simple and latest software for schematic electrical circuit designing and PCB layout. This is an expandable, flexible and scriptable EDA (Electronic Design Automation)/ ECAD (Electronic Computer Aided design) application with PCB layout editor, schematic capture editor, auto-router and CAM (Computer Aided Manufacturing) and BOM (Bill of Material) tools, developed by CadSoft Computer.

To write program using Embedded $\mathrm{C}$ programming language for ARM7 microprocessor, to process the functions of the peripherals like air flow (MIC) sensor, accelerometer and ZigBee modules, etc. we used Keil $\mu$ Vision software, which is an Integrated Development Environment (IDE) for ARM microprocessors.

\section{Algorithm}

In mathematics, computer, electrical and electronics science an Algorithm is a self-contained step by step set of operations, to be performed. The algorithms of our Control Unit and Wheelchair Unit are given below:-

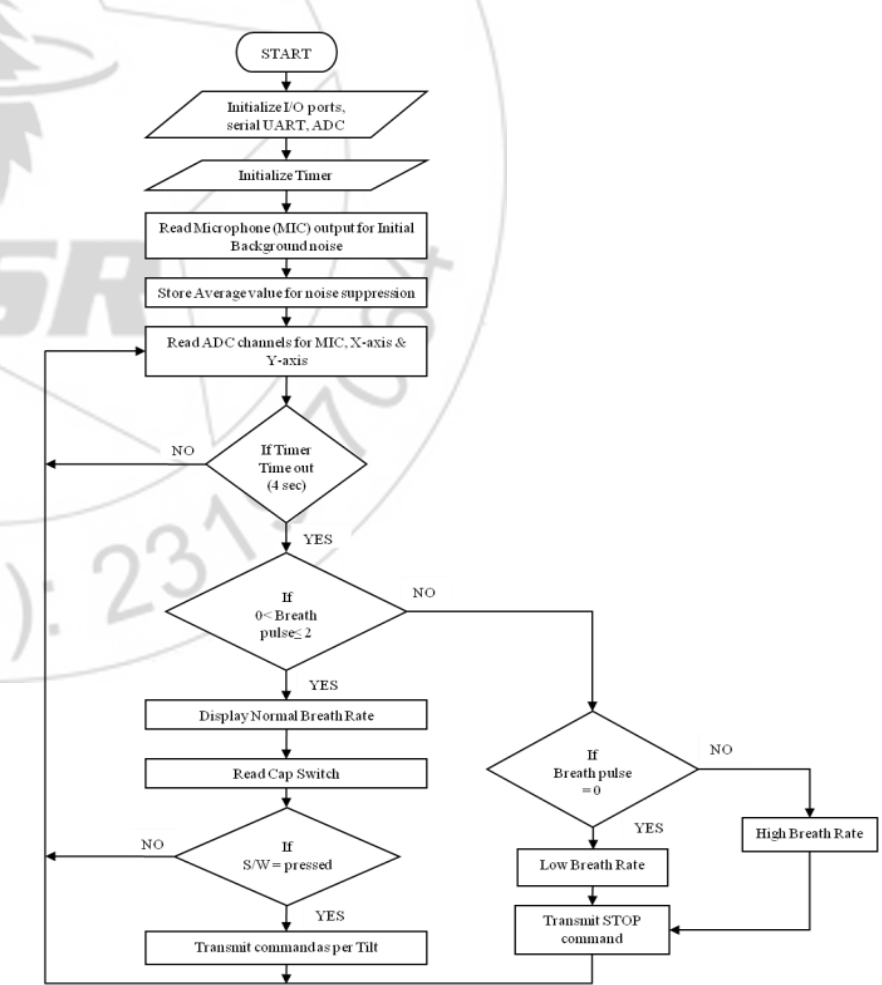

Figure 14: Flow Chart of Control Unit 


\section{International Journal of Science and Research (IJSR) \\ ISSN (Online): 2319-7064}

Index Copernicus Value (2013): 6.14 | Impact Factor (2015): 6.391

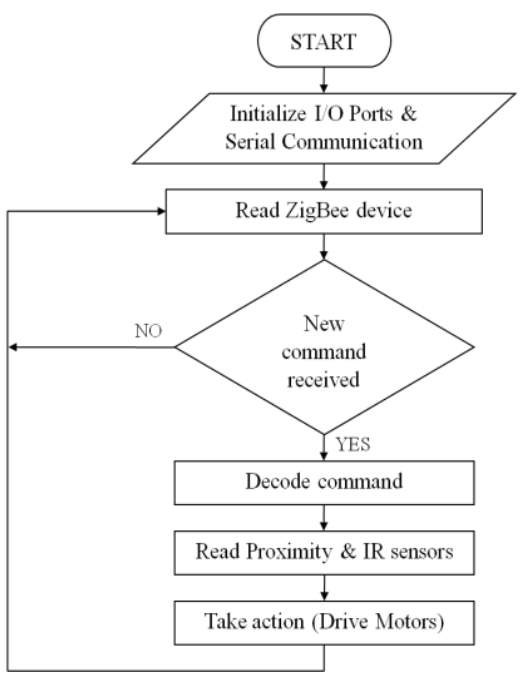

Figure 15: Flow Chart of Wheelchair Unit

\section{Experiments}

In this project wheelchair is operated using human breath pressure combined with head motion and to sense the breath pressure and head motion data, MIC and Accelerometer is used. 10 bit ADC that is already present in LPC2148 microcontroller converts these analog data from MIC and ADXL335 device into digital output.

\subsection{Breath Processing System}



Figure 16: Breath Processing System

In this system, MIC acts as a transducer by which human breath variation or vibration is converted into electrical signal. MIC takes breath pressure as input and output is given to signal conditioning circuit. Signal conditioning circuit (LM386N IC) is used to suppress surrounding noise disturbance and enhance input breath pressure signal. This enhanced analog output $(<10 \mathrm{mV})$ is converted into digital signal by ADC, which is already inbuilt in microcontroller. One bit resolution of ADC is $3.22 \mathrm{mV}$. SAR (Successive Approximation Resister) is used for conversion of analog input into digital output.

$$
\mathbf{D}=\frac{\mathbf{A}}{\mathbf{R}}
$$

\section{$\mathrm{D}=$ Digital output}

$\mathrm{A}=$ Analog input from LM386 IC in $\mathrm{mV}$

$\mathrm{R}=$ One bit resolution of $\mathrm{ADC}(3.22 \mathrm{mV})$

Digital output of ADC goes through Digital Signal Processing and processed data is stored as signal value in microcontroller. Average value of background noise suppression, which is considered by microcontroller is less than or equal to $60 \mathrm{mV}$. According to all stored values breath rate of person is decided. First wheelchair system will activate by Breath pressure (inhaling and exhaling) captured by MIC is a combined process with accelerometer device. Microcontroller will transmit commands through ZigBee module only if the breathing of person will be normal. Breath rate of user also indicates normal health condition of person. If breath rate of user decreases or increases (Low and High Breath rates), then buzzer will generate sound signal and wheelchair will go in stop state. Changed breath rates are displayed on LCD. LCD is mounted in front of the wheelchair, so anyone can see the changing of user's breath rate. The main measurement and control component is a small circuit board that is placed on cap. Human breathing conditions i.e. Normal, Low and High breath rate is given below [1].

\subsubsection{Normal Breath Rate}

Human breathing count is approximate 12-17 bpm (Breath per minute). So, one or two breath pulse in $4 \mathrm{sec}$ is considered for Normal breath rate. If one or two breath pulses found in $4 \mathrm{sec}$ and peak of all breath pulses crossed threshold level $(\leq 60 \mathrm{mV})$, then condition of Normal breath rate is satisfied and this will display on LCD.

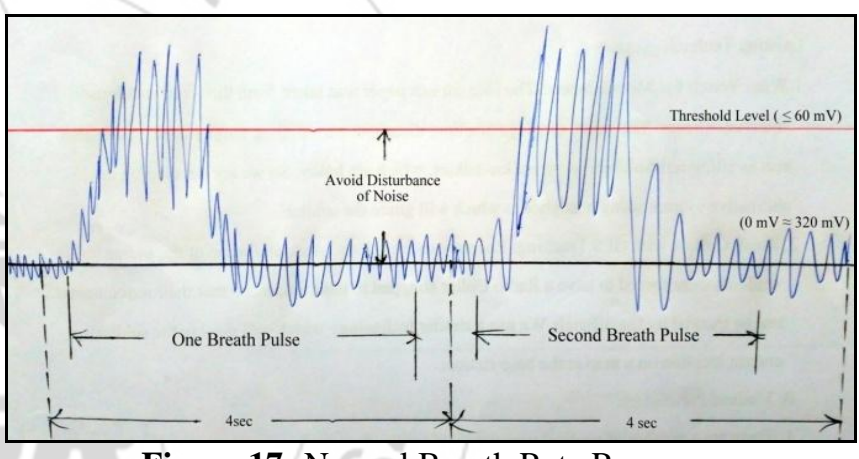

Figure 17: Normal Breath Rate Response

\subsubsection{Low Breath Rate}

If there is no peak of breath pressure (pulses) found in consecutive time period $(\approx 12 \mathrm{sec})$, that means no peak of breath pulses crossed threshold level in $12 \mathrm{sec}$, then the condition of Low breath rate is satisfied.

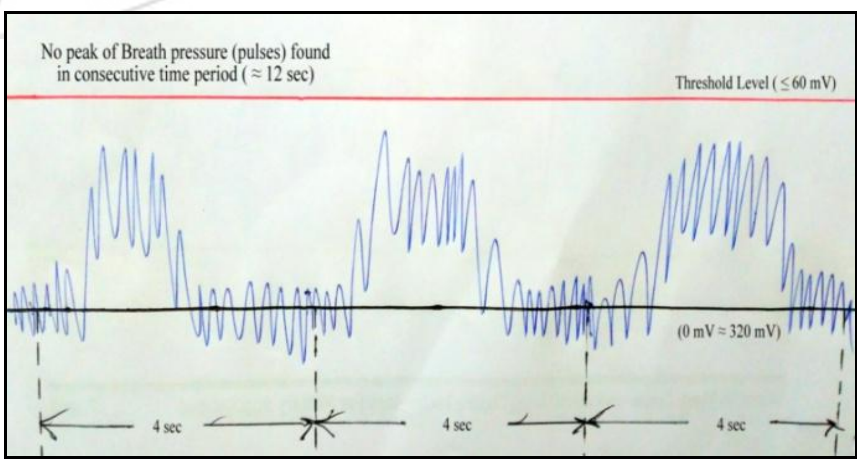

Figure 18: Low Breath Rate Response

\subsubsection{High Breath Rate}

There are two conditions, which are analysed with all experiments of breathing process, in High breath rate.

\section{Volume 5 Issue 5, May 2016 www.ijsr.net}




\section{International Journal of Science and Research (IJSR) \\ ISSN (Online): 2319-7064}

Index Copernicus Value (2013): 6.14 | Impact Factor (2015): 6.391

(a) Continue High Breath Pulses

Total sum of magnitudes of all breath pulses above the threshold level is considered as Continue High breath rate. Process carried out through the microprocessor (ARM7) is described by given formula.

$$
\mathrm{M} \approx \mathbf{N} * \mathbf{A}
$$

$\mathrm{M}=$ magnitudes of breath pulses

$\mathrm{N}=$ number of one breath pulse

$\mathrm{A}=$ average value after noise suppression $(\approx 320 \mathrm{mV})$

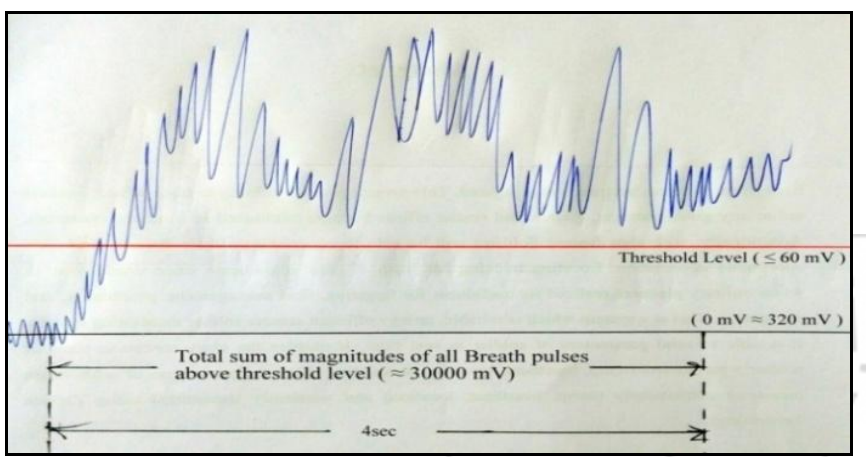

Figure 19: Response of Continue High Breath Pulses

\section{(b) More than Two Breath Pulses}

If more than two breath pulses are found in time period of $4 \mathrm{sec}$, then this also indicates the condition of High breath rate.

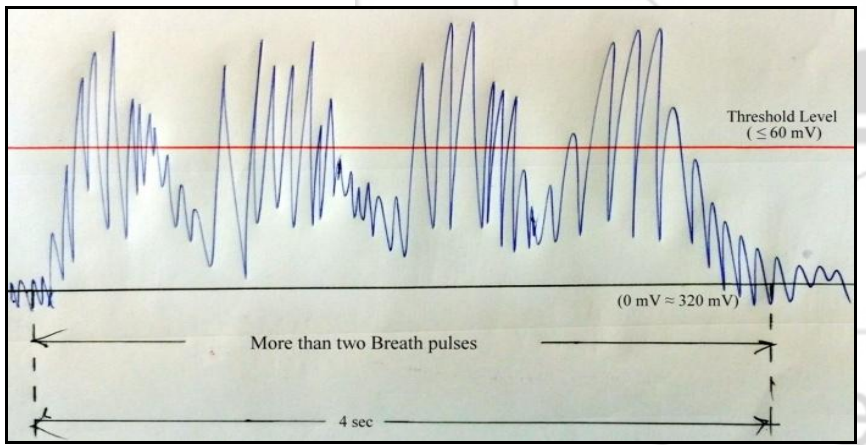

Figure 20: Response of More Than Two Breath Pulses

In both condition of Low and High breath rate, microcontroller continuously transmit only STOP command to the wheelchair unit. Therefore the wheelchair will not move in any direction.

\subsection{Head Motion System}

The prototype consists of the digital system (an accelerometer and a microcontroller). The accelerometer is used to collect head motion data. A novel algorithm is implemented for processing the sensors data using a microcontroller [1].
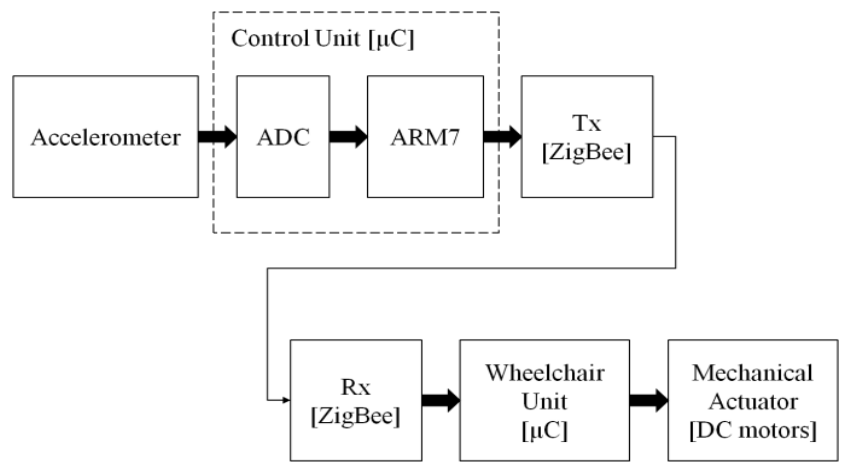

Figure 21: Head Motion System

An accelerometer (ADXL335) device is an electromechanical device that measures acceleration forces and tilting angle from the ground and gives analog output from X-OUT and Y-OUT pins which is in the form of electrical signal. When ADXL335 device is at static or stable position $\left(0^{\circ}\right)$, it gives $1.6 \mathrm{~V}$ as output for both $\mathrm{X}$-axis and $\mathrm{Y}$ axis. This electrical value is divided by 1 bit resolution of $\mathrm{ADC}$ and the calculated values of both axes are given to the microprocessor (ARM7). The process carried out in ADC is given below.

$$
\mathbf{D}= \pm \frac{\mathbf{A}}{\mathbf{R}}
$$

\section{$\mathrm{D}=$ digital value for both $\mathrm{X}$ and $\mathrm{Y}$ axis \\ $\mathrm{A}=$ analog input from accelerometer \\ $\mathrm{R}=1$ bit resolution of $\mathrm{ADC}(3.2 \mathrm{mV})$}

Microcontrollers continuously store all values and wait for MIC data. According to breath pressure data, it sends commands to wheelchair unit. If breath rate is normal, then it sends forward, backward, right and left commands, else it sends Stop command. The direction of the wheelchair and its speed depend on how the user tilts their head. If the user tilts his/ her head at an angle (more than $30^{\circ}$ ) to any desired direction like forward, backward, left and right, the wheelchair will turn in that direction.

\subsection{Head Motion Recognition Algorithm}

Since a set of possible movement commands in this case are very small and also very limited. Thus, the control of the system allows the user to give only four different commands forward, backward, left and right, which are recognized by the accelerometer device. In fig. 22 positive and negative threshold setting for both $\mathrm{X}$ and $\mathrm{Y}$ axes are given. Positive threshold at $\mathrm{Y}$-axis is selected for forward motion and negative threshold at $\mathrm{Y}$-axis is for backward motion. Positive threshold at $\mathrm{X}$-axis is selected for right motion and negative threshold at X-axis is for left motion. The meaning of each of the commands is easy and depends on the present wheelchair state. 


\section{International Journal of Science and Research (IJSR) \\ ISSN (Online): 2319-7064}

Index Copernicus Value (2013): 6.14 | Impact Factor (2015): 6.391

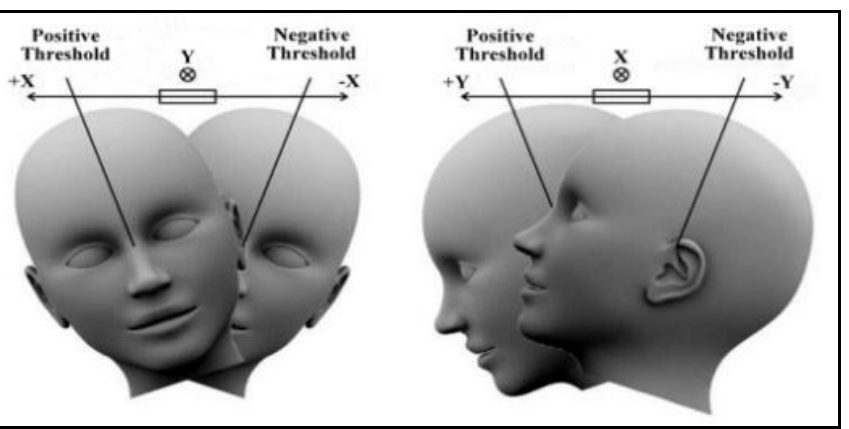

Figure 22: An Example of Threshold Setting

We have defined six different wheelchair states, which are state of still, forward motion, backward motion, left motion and right motion. If the wheelchair is in the "state of still" position, the command "forward" will move it into forward direction and the command "backward" will move it into backward direction. If user gives a command "left" or "right", while in the "state of still" position, then wheelchair will move in that directions. When the wheelchair is in any motion states, the movements will start when the user passes the threshold circle which is shown in Fig.23. It stops when the user returns the head in the starting position (state of still) [1], [9].

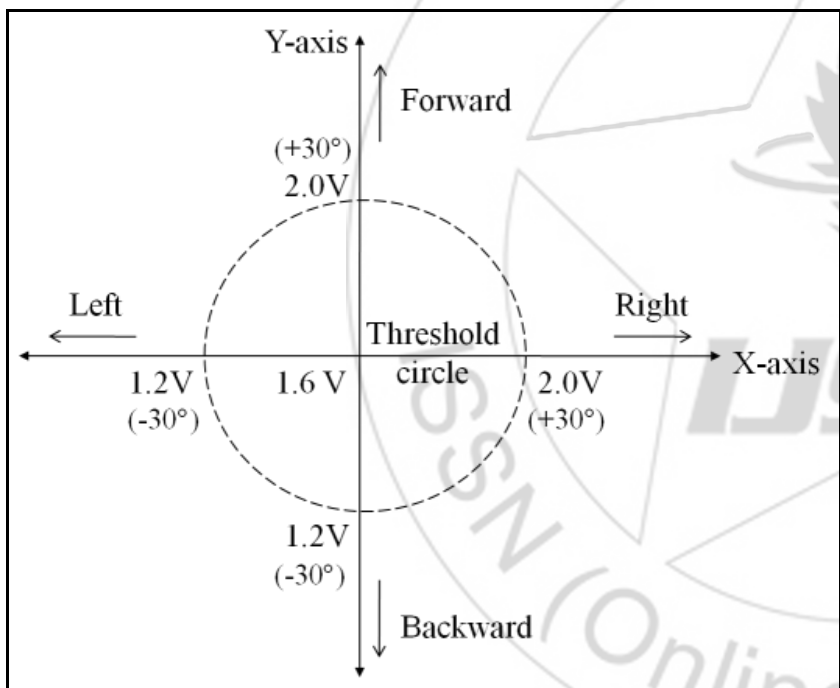

Figure 23: Accelerometer (ADXL335) X-axis and $\mathrm{Y}$-axis Data with Threshold Circle

In Fig.23 all direction of the wheelchair is given with threshold circle. Threshold circle is bounded by two upper and lower voltages (i.e.1.2 $\mathrm{V}$ to $2.0 \mathrm{~V}$ ) at both $\mathrm{X}$ and $\mathrm{Y}$ axes, which is measured by accelerometer device. Accelerometer gives analog output in the form of electrical signal (voltage) and analog data is converted into digital values by ADC. These values are compared in microcontroller of control unit that are used for the movement of wheelchair. If the input voltage is between the threshold circle $(1.2 \mathrm{~V}$ to $2 \mathrm{~V})$, then wheelchair motion will not move. Condition for wheelchair movement is above $+30^{\circ}$ for forward and right movements and above $-30^{\circ}$ for backward and left movements at both axes. If voltage is above the threshold level, then motion of wheelchair starts and it will move in desired direction.

\section{Results}

We obtained three conditions by which motion of embedded vehicle (wheelchair) is controlled. Table 1 indicates motion of wheelchair when breath rate of person is normal (i.e. when cap switch is pressed). Table 2 shows motion of wheelchair when breath of user is high or low. In case of high or low breath rate, the wheelchair will stop and until the breath rate of user does not become normal, it will not move in any direction. If cap is not installed (i.e. cap switch is not pressed), then wheelchair will not move. Results of our embedded system are shown below.

Table 1: Normal Breath Rate

\begin{tabular}{|c|c|c|c|c|c|}
\hline \multirow{2}{*}{$\begin{array}{c}\text { CAP } \\
\text { INSTALLED }\end{array}$} & \multirow{2}{*}{$\begin{array}{l}\text { BREATH } \\
\text { RATE }\end{array}$} & \multicolumn{2}{|c|}{ ACCELEROMETER } & \multirow{2}{*}{$\begin{array}{l}\text { TRANSMIT } \\
\text { COMMAND }\end{array}$} & \multirow[t]{2}{*}{ BUZZER } \\
\hline & & $\mathrm{X}$-axis & Y-axis & & \\
\hline $\begin{array}{c}\text { No } \\
\text { (Switch is not pressed) }\end{array}$ & $\mathrm{x}$ & $\mathrm{x}$ & $\mathrm{x}$ & STOP & BEEP \\
\hline $\begin{array}{c}\text { YES } \\
\text { (Switch is pressed) }\end{array}$ & NORMAL & $\begin{array}{c}-30^{\circ}<\mathrm{X}<+30^{\circ} \\
(1.2 \mathrm{~V} \text { TO } 2.0 \mathrm{~V})\end{array}$ & $\begin{array}{l}>+30^{\circ} \\
(2.0 \mathrm{~V})\end{array}$ & FORWARD & OFF \\
\hline $\begin{array}{c}\text { YES } \\
\text { (Switch is pressed) }\end{array}$ & NORMAL & $\begin{array}{l}-30^{\circ}<\mathrm{X}<+30^{\circ} \\
(1.2 \mathrm{~V} \text { To } 2.0 \mathrm{~V})\end{array}$ & $\begin{array}{l}>-30^{\circ} \\
(1.2 \mathrm{~V})\end{array}$ & BACKWARD & OFF \\
\hline $\begin{array}{c}\text { YES } \\
\text { (Switch is pressed) }\end{array}$ & NORMAL & $\begin{array}{l}>-30^{\circ} \\
(1.2 \mathrm{~V})\end{array}$ & $\begin{array}{c}-30^{\circ}<\text { Y }<+30^{\circ} \\
(1.2 \mathrm{~V} \text { TO } 2.0 \mathrm{~V})\end{array}$ & LEFT & OFF \\
\hline $\begin{array}{c}\text { YES } \\
\text { (Switch is pressed) }\end{array}$ & NORMAL & $\begin{array}{l}>+30^{\circ} \\
(2.0 \mathrm{~V})\end{array}$ & $\begin{array}{l}-30^{\circ}<\mathrm{Y}<+30^{\circ} \\
(1.2 \mathrm{~V} \text { TO } 2.0 \mathrm{~V})\end{array}$ & RIGHT & OFF \\
\hline
\end{tabular}

Table 2: Low and High Breath Rate

\begin{tabular}{||c|c|c|c|c|c||}
\hline \multirow{2}{*}{$\begin{array}{c}\text { CAP } \\
\text { INSTALLED }\end{array}$} & $\begin{array}{c}\text { BREATH } \\
\text { RATE }\end{array}$ & \multicolumn{2}{|l|}{ ACCELEROMETER } & \multirow{2}{*}{$\begin{array}{c}\text { TRANSMIT } \\
\text { COMMAND }\end{array}$} & BUZZER \\
\cline { 3 - 5 } & X-axis & Y-axis & \\
\hline $\begin{array}{c}\text { YES } \\
\text { (Switch is pressed) }\end{array}$ & LOW & $\mathrm{x}$ & $\mathrm{x}$ & STOP & BEEP \\
\hline $\begin{array}{c}\text { YES } \\
\text { (Switch is pressed) }\end{array}$ & HIGH & $\mathrm{x}$ & $\mathrm{x}$ & STOP & BEEP \\
\hline
\end{tabular}

\section{Conclusion}

In this paper a microcontroller system that enables standard electric wheelchair control by normal breath of user and head motion is presented. There are some drawbacks of existing wheelchair technologies, which are designed and implemented for quadriplegic people. So this is a unique technology to control the wheelchair. In this paper, wheelchair technology using normal breath pressure combined with motion of head is better option for the quadriplegic people. The wheelchair system is activated by inhaling and exhaling the breath of the person. The embedded wheelchair is controlled automatically by wireless sensor network (WSN). Learning to operate the wheelchair is very easy. Person just needs to breathe in and out to activate the system and move wheelchair into the required direction with head motion (Accelerometer). In this technology person's health is also monitored with the help of user's breath.

This system can be implemented with automatically recharging the battery using alternator during movement of 


\section{International Journal of Science and Research (IJSR) \\ ISSN (Online): 2319-7064}

Index Copernicus Value (2013): 6.14 | Impact Factor (2015): 6.391

the wheelchair or using solar panel. Power of Wheelchair unit will automatically $\mathrm{ON}$ and OFF when control unit send commands. A Global Positioning System (GPS) can be installed on wheelchair unit to track the position of the user. Finding more power economic methods for implementing when the system becomes precise and reliable enough perform an experiment which would include actual quadriplegics.

\section{References}

[1] Umeshkumar Jaiswar, Sanjna Repal, "A Review on Real Time Breath Processing Based Embedded Wheelchair for Quadriplegic People", International Journal of Innovative Research in Science, Engineering and Technology, ISSN: 2319-8753, Volume 4, Issue 7, DOI: 10.15680/IJIRSET.2015.0407101, July 2015, pp: (5575$5587)$.

[2] Motoji Yamamoto, Takeshi Ikeda, Yoshinobu Sasaki, "Real Time Analog Input Device Using Breath Pressure for the Operation of Powered Wheelchair", 2008 IEEE International Conference on Robotics and Automation, Pasadena, CA, USA, May 19-23, 2008, 978-1-42441647-9/08/\$25.00 (C) 2008 IEEE, pp: (3914-3919).

[3] H.T. Nguyen, L.M. King, G. Knight, "Real Time Head Movement System and Embedded Linux Implementation for the Control of Power Wheelchairs", Proceedings of the 26th Annual International Conference of the IEEE EMBS, San Francisco, CA, USA, September 1-5, 2004, 0-7803-8439-3/04/\$20.00 (C) 2004 IEEE, pp: (48924895).

[4] D.J. Kupetz, S.A. Wentzell, B.F. Busha, "Head Motion Controlled Power Wheelchair", Bioengineering Conference, Proceedings of the 2010 IEEE 36th Annual Northeast, March 26-28, 2010, 978-1-4244-6924 6/10/\$26.00 @ 2010 IEEE, pp: (1-2)

[5] Ericka Janet Rechy-Ramirez, Huosheng $\mathrm{Hu}$ and Klaus McDonald-Maier "Head Movements Based Control of an Intelligent Wheelchair in an Indoor Environment", Proceeding of the 2012 IEEE International conference on Robotics and Biomimetics, Guangzhou, China, December 11-14, 2012, 978-1-4673-2126-6/12/\$31.00 (C) 2012 IEEE, pp: (1464-1469).

[6] Ericka Janet Rechy-Ramirez and Huosheng $\mathrm{Hu}$, "Bimodal Human Machine Interface for Controlling an Intelligent Wheelchair", Fourth International Conference on Emerging Security Technologies, September 9-11, 2013, 978-0-7695-5077-0/13 (C) 2013 IEEE, DOI: 10.1109/EST.2013.19, pp: (66-70)

[7] D.A. Craig, H.T. Nguyen, "Adaptive EEG Thought Pattern Classifier for Advanced Wheelchair Control", Proceedings of the $29^{\text {th }}$ Annual International Conference of the IEEE EMBS Cite Internationale, Lyon, France, August 23-26, 2007, 1-4244-0788-5/07/\$20.00 (C) 2007 IEEE, pp: (2544-2547).

[8] Diksha Goyal and Dr. S.P.S. Saini, "Accelerometer Based Hand Gesture Controlled Wheelchair", International Journal on Emerging Technologies, ISSN: 2249-3255, Volume 4, Issue 2, June 2013, pp: (15-20).

[9] Aleksandar Pajkanovic, Branko Dokic, "Wheelchair Controlled by Head Motion", Serbian Journal of
Electrical Engineering, ISSN: 2217-7183, Volume 10, No. 1, February 2013, DOI: 10.2298/SJEE1301135P, pp: (135-151).

[10] Anoop.K.J, Inbaezhilan, Sathish Raj, Ramaseenivasan and CholaPandian, "Designing and Modeling of Voice Controlled Wheelchair Incorporated with Home Automation", International Journal of Advanced Research in Electrical, Electronics and Instrumentation Engineering, ISSN: 2278-8875, Volume 3, Issue 2, April 2014, pp: (53-60)

[11]Jzau-Sheng Lin, Win Ching Yang, "Wireless Brain Computer Interface for Electric Wheelchairs with EEG and Eye Blinking Signals", International Journal of Innovative Computing Information and Control, ISSN: 1349-4198, Volume 8, Number 9, September 2012, pp: (6011-6024)

[12] NXP Semiconductors, UM10139, LPC 214X User Manual, Rev. 4, 23 April 2012, pp: (1-354).

[13] Nordic Semiconductors, nRF24L01+ Single Chip $2.4 \mathrm{GHz}$ Transceiver, Product Specification v1.0, September 2008, pp: (1-8)

\section{Authors Profile}

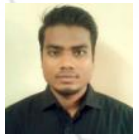

Umeshkumar L. Jaiswar is currently pursuing M.E. in Electronics and Telecommunication from MCT's Rajiv Gandhi Institute of Technology, Mumbai University. His area of interest is Wireless Communication and Embedded System design and implementation. $\mathrm{He}$ has completed his B.E. in Electronics and Telecommunication from JES's A.C. Patil College of Engineering, Mumbai University.

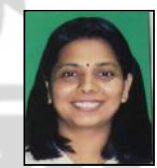

Sanjna S. Repal is currently working as Assistant Professor in MCT's Rajiv Gandhi Institute of Technology, Mumbai University. Her area of interest is design of Microprocessor, Microcontroller and VLSI circuits and systems. She has completed her B.E. in Electrical Engineering from Sardar Patel College of Engineering, Mumbai University and M.E. in Electronics Engineering from Fr. Conceicao Rodrigues College of Engineering, Mumbai University. 